\title{
THE EFFECT OF A POST OXIDATION IN-SITU NITROGEN ANNEAL ON SI SURFACE PASSIVATION
}

\author{
Hao Jin, K.J.Weber, and A.W.Blakers \\ Centre for Sustainable Energy Systems, Faculty of Engineering and Information Technology, The Australian National \\ University, Canberra ACT 0200, Australia, email hao.jin@anu.edu.au
}

\begin{abstract}
The thermal stability of $\mathrm{Si} / \mathrm{SiO}_{2}$ stacks and $\mathrm{Si} / \mathrm{SiO}_{2} /$ $\mathrm{Si}_{3} \mathrm{~N}_{4}$ stacks with and without post oxidation in-situ anneal in nitrogen is investigated by Quasi-steady state photoconductivity decay (QSSPCD) and Electronic Paramagnetic Resonance (EPR). With in-situ annealing in nitrogen, the $\mathrm{Si}_{-} \mathrm{SiO}_{2}$ interface shows a reduced density of paramagnetic defects and better thermal stability. $\mathrm{Si} / \mathrm{SiO}_{2} / \mathrm{Si}_{3} \mathrm{~N}_{4}$ stacks have a much slower depassivation rate than $\mathrm{Si} / \mathrm{SiO}_{2}$ stacks due to hydrogen stored in nitride layer.
\end{abstract}

\section{INTRODUCTION:}

Thermally grown oxide layers are well known to provide good surface passivation. While for most commercial cells PECVD SiN is now the material of choice for surface passivation, there are applications where a thermally grown oxide is very useful, such as some novel cell designs, for example SLIVER cells, which utilize an oxide / LPCVD silicon nitride stack as an antireflection coating. $[1,2,3]$ It is therefore important to understand in detail how surface recombination at the $\mathrm{Si}-\mathrm{SiO}_{2}$ interface can be minimised. Also the thermal stability of the interface passivation is of interest, since the interface is subjected to high temperatures both during and possibly after the deposition of the silicon nitride, which is usually carried out at $\sim 775^{\circ} \mathrm{C}$.

Post oxidation in-situ anneals in nitrogen or argon at high temperatures are known to be an effective method to improve the quality of the $\mathrm{Si}-\mathrm{SiO}_{2}$ interface following thermal oxidation, as measured by a reduction in surface recombination.

In this paper, the effects of in-situ $\mathrm{N}_{2}$ anneals on the $\mathrm{Si}_{-} \mathrm{SiO}_{2}$ interface properties are discussed. (100), (111) and textured $\mathrm{Si}$ wafers were used for the experiments since they have different sensitivity to thermal treatments. $\mathrm{Si} / \mathrm{SiO}_{2}$ stacks and $\mathrm{Si} / \mathrm{SiO}_{2} /$ LPCVD SiN stacks were investigated. Rapid Thermal Anneals (RTAs) were used to investigate the thermal stability of the passivation of oxidized surfaces. Quasi-Steady State Photoconductivity Decay (QSSPCD) and Electron Paramagnetic Resonance (EPR) measurements were used to gain information on surface recombination and paramagnetic defect densities, respectively.

\section{EXPERIMENTAL DETAILS:}

Float Zoned (FZ), (100) oriented, p-type, $100 \Omega-\mathrm{cm}, 500 \mu \mathrm{m}$

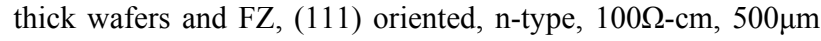
thick wafers were taken as the starting materials for QSSPCD measurement. CZ, p-type, $\sim 10 \Omega / \mathrm{cm}, 500 \mu \mathrm{m}$ thickness (111) wafers were used in the Electron Paramagnetic Resonance (EPR) measurements. To fit into the cavity, EPR samples were cut by a diamond saw into $25 \mathrm{~mm} \times 2.5 \mathrm{~mm}$ pieces. All samples are initially etched in 10:1 $\mathrm{HNO}_{3}$ : HF solution until shiny. Some (100) wafers were textured to form inverted pyramids on top.

After a standard RCA clean, all samples were passivated by a thermally grown oxide $(\sim 50 \mathrm{~nm})$ in dry oxygen at $1000^{\circ} \mathrm{C}$. Selected wafers received an in-situ $\mathrm{N}_{2}$ anneal after oxidation at $1000^{\circ} \mathrm{C}$ for 30 minutes. All QSSPCD wafers had a forming gas anneal $\left(5 \% \mathrm{H}_{2}\right.$ in $95 \%$ argon) at $400^{\circ} \mathrm{C}$ for $30 \mathrm{~min}$. LPCVD $\mathrm{Si}_{3} \mathrm{~N}_{4}$ deposition was done at $775^{\circ} \mathrm{C}$ and 0.5 torr, with an ammonia to DCS flow ratio of $4: 1$, to give a $50 \mathrm{~nm}$ nitride layer on selected QSSPCD samples. Isochronal and isothermal RTAs were performed on some QSSPCD samples to test the thermal stability.

RTA at $800^{\circ} \mathrm{C}$ in high flow dry nitrogen for 3 min was done on EPR samples to completely dehydrogenate the (111) $\mathrm{Si}_{-} \mathrm{SiO}_{2}$ interface, and thus allow measurement of the total paramagnetic interface defect $\left(\mathrm{P}_{\mathrm{b}}\right.$ centre $)$ density. This treatment is known not to generate significant amounts of additional defects.

QSSPCD measurements were carried out using a white flash with a known light spectrum. The measurements were modeled using PC1D[4], for different values of the surface recombination velocity and the light intensity, and assuming a very high bulk lifetime $(30 \mathrm{~ms})$. This allowed derivation of an empirical equation relating the measured minority carrier lifetime at a particular injection level to the effective surface recombination velocity, $\mathrm{S}_{\text {eff }}$, valid for $\mathrm{S}_{\text {eff }}$ values of no more than $\sim 7000 \mathrm{~cm} / \mathrm{s}$. The $\mathrm{S}_{\text {eff }}$ was estimated for the highest effective lifetime at the injection level range of $1 \times 10^{14} / \mathrm{cm}^{2}$ to $2 \times 10^{14} / \mathrm{cm}^{2}$.

EPR spectra were obtained with a Bruker 300 X-band (9.44GHZ) spectrometer. Measurements were taken using 5G modulation and $20 \mu \mathrm{W}$ microwave power at a temperature of $8 \mathrm{~K}$. The low microwave power is carefully chosen to prevent signal 
saturation. The paramagnetic $\mathrm{P}_{\mathrm{b}}$ centre, known to be by far the dominant defect on (111) surfaces, can be detected from these measurements. The $\left[\mathrm{P}_{\mathrm{b}}\right]$ concentration was calculated by double integrating the original signal and comparing with a standard solution signal, which is obtained under similar conditions.

\section{RESULTS AND DISCUSSION}

\section{Effect of in-situ $\mathrm{N}_{2}$ anneal}

Figure 1 shows the effect of the in-situ $\mathrm{N}_{2}$ anneal on the lifetime measured directly after oxidation. The line with open circles represents oxidised wafers without in-situ anneal in $\mathrm{N}_{2}$, while the line with solid circles represents wafers with in-situ $\mathrm{N}_{2}$ anneal. The effective lifetime for the oxidized sample with in-situ $\mathrm{N}_{2}$ anneal is higher than the oxidized sample without insitu $\mathrm{N}_{2}$ anneal at all injection levels. The bulk lifetime for both samples should be the same, therefore, the difference in the effective lifetime must be due to a difference in surface passivation. Clearly oxidation with an in-situ $\mathrm{N}_{2}$ anneal results in a better passivated surface.

On (111) silicon surfaces, a $\mathrm{P}_{\mathrm{b}}$ defect is an unpaired electron on a trivalently bonded silicon atom generated at the $\mathrm{Si}-\mathrm{SiO}_{2}$ interface as the result of mismatch. $\mathrm{P}_{\mathrm{b}}$ centres are initially generated during the oxidation process. The EPR measurements indicate that the in-situ $\mathrm{N}_{2}$ anneal leads to a significant reduction in the $\mathrm{P}_{b}$ centre density, with $\left[\mathrm{P}_{\mathrm{b}}\right]$ of $4.6 \times 10^{12} / \mathrm{cm}^{2}$ for a sample with in-situ anneal compared with $1.1 \times 10^{13} / \mathrm{cm}^{2}$ without an anneal.

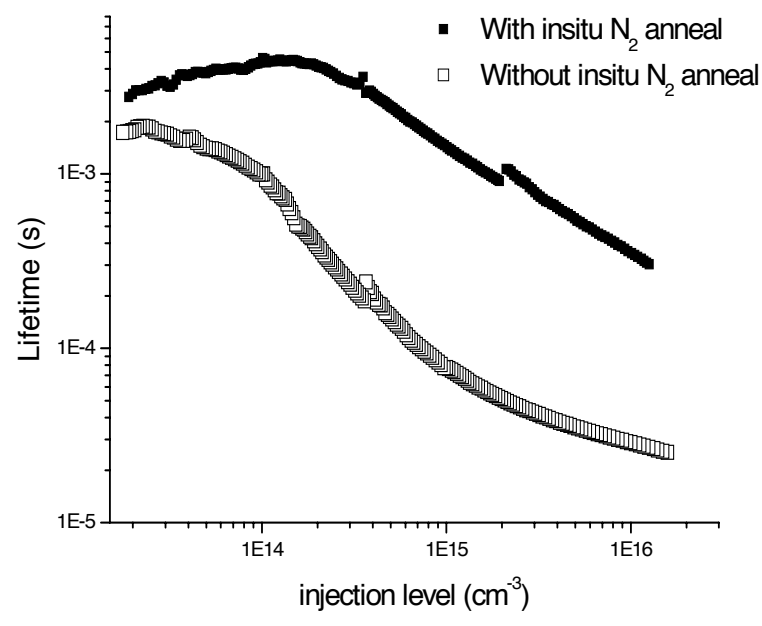

Fig 1. Effective lifetime vs injection level

\section{In-situ N2 Anneal effects on Si-SiO2 thermal stability under RTA}

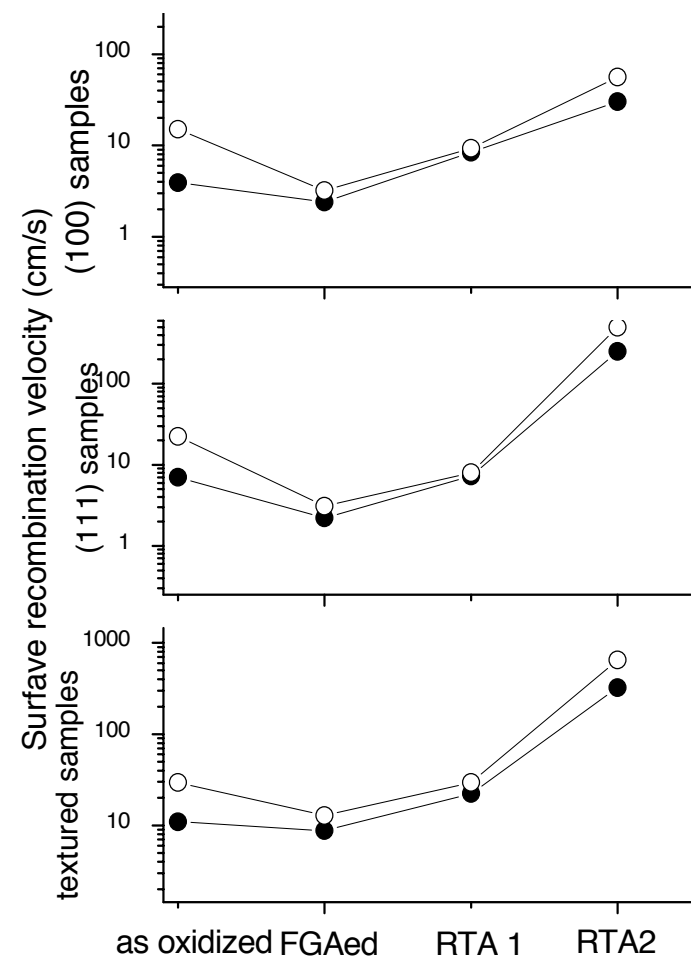

Figure 2. surface recombination velocity vs thermal treatments

Figure 2 shows the effective surface recombination velocities of (100), (111) and textured, oxidized wafers with and without an in-situ $\mathrm{N}_{2}$ anneal, and the effect of thermal treatments on $\mathrm{S}_{\text {eff }}$.

In figure 2 , the open datum presents the values from 'without in-situ $\mathrm{N}_{2}$ anneal' samples. The solid datum presents the values from 'with in-situ $\mathrm{N}_{2}$ anneal' samples. 'As oxidized' represents values measured just after oxidation. 'FGAed' represents the values following forming gas annealing. 'RTA1' and 'RTA2' were performed at $500^{\circ} \mathrm{C}$ for 3 minutes and $600^{\circ} \mathrm{C}$ for 3 minutes in $\mathrm{N}_{2}$ gas respectively.

All of the (100), (111) and textured orientations display the same trend. After oxidation, samples with in-situ $\mathrm{N}_{2}$ anneal have lower recombination velocity. The FGA process introduces hydrogen to the $\mathrm{Si}-\mathrm{SiO}_{2}$ interface and lowers $\mathrm{S}_{\text {eff }}$. 'RTA1' increases $S_{\text {eff. }}$ The difference between samples with and without in-situ $\mathrm{N}_{2}$ anneal is small at these two steps. As samples were FGAed, the majority of dangling bonds at the interface are passivated with hydrogen. An RTA at $500^{\circ} \mathrm{C}$ for 3 mins does not lead to a significant release of hydrogen from the interface. However, after RTA2, a significant fraction of hydrogen has been driven away from the $\mathrm{Si}-\mathrm{SiO}_{2}$ interface. A bigger difference in $\mathrm{S}_{\text {eff }}$ between samples with and without in-situ $\mathrm{N}_{2}$ anneal is apparent. At this stage, the in-situ annealed samples 
have only around half the $S_{\text {eff }}$ values of the samples without insitu anneals.

It can also be concluded from figure 2 that (100), (111) and textured samples display a different depassivation rate. From step 'RTA1' to 'RTA2', the textured samples have the most rapid and (100) samples the slowest depassivation rate. The behaviour of (111) samples is similar to that of the textured samples. These observations are quite consistent with our other results presented elsewhere [4].

\section{In-situ $\mathrm{N}_{2}$ Anneal effects on $\mathrm{Si} / \mathrm{SiO}_{2} / \mathrm{SiN}$ stacks under RTA}

Figures 3 and 4 show the effect of an in-situ $\mathrm{N}_{2}$ anneal on nitride stacks after isochronal and isothermal RTAs.

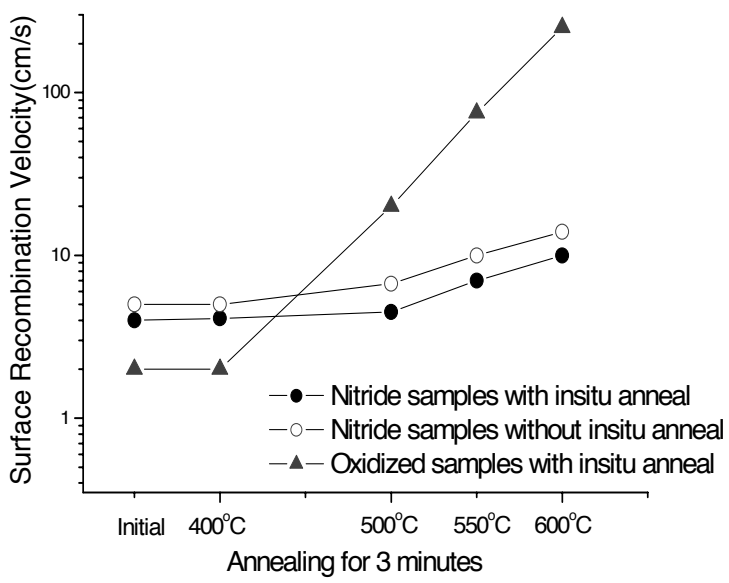

Figure3. isochronal anneal on $\mathrm{Si} / \mathrm{SiO} 2 / \mathrm{SiN}$ stacks

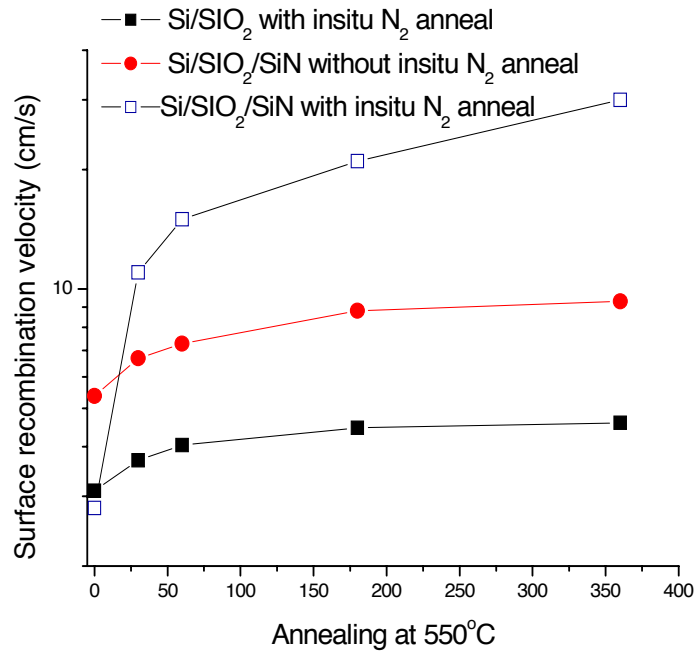

Figure 4. isothermal anneal on $\mathrm{Si} / \mathrm{SiO} 2 / \mathrm{SiN}$ stacks

In figure 3, (111) Si wafers were used. The 'initial' value for oxidized samples was taken after oxidation, an in-situ $\mathrm{N}_{2}$ anneal and a FGA. The 'initial' values for nitride samples were taken after oxidation with / without an in-situ $\mathrm{N}_{2}$ anneal, an
FGA and LPCVD deposition. Since the deposition was carried out at $775^{\circ} \mathrm{C}$, the 'initial' values for nitride samples are higher than for the as oxidized samples.

As the annealing temperature increases, the nitride samples display a better thermal stability than the oxidized samples. With an in-situ $\mathrm{N}_{2}$ anneal, the nitride stacks have the lowest $\mathrm{S}_{\text {eff }}$ values after RTAs from $500^{\circ} \mathrm{C}$ to $600^{\circ} \mathrm{C}$. The reason for the increased stability of the samples with a nitride is likely to be the release of hydrogen from the nitride at elevated temperatures, which provides an additional source of hydrogen for re-passivation of the $\mathrm{Si}-\mathrm{SiO}_{2}$ interface.

\section{CONCLUSION}

Post oxidation in-situ annealing in nitrogen reduces the density of interfacial defects generated during the oxidation process. Nitrogen annealed (100), (111) and textured, oxidised samples display lower $\mathrm{S}_{\text {eff }}$ values and slower depasivation rates than samples without nitrogen anneals. With a nitrogen anneal, $\mathrm{Si} / \mathrm{SiO}_{2} / \mathrm{SiN}$ stacks show good thermal stability after isochronal and isothermal RTAs.

\section{REFERENCES}

1. M.J. McCann, K.J. Weber and A.W. Blakers, Prog. Photovolt., 13 , 195 (2005)

2. M.J. McCann, K.J. Weber and A.W. Blakers, Proceedings 3rd World Conference on Photovoltaic Solar Energy Conversion, (2003)

3. M.J. McCann, M.J. Stocks, K.J. Weber and A.W. Blakers, Proceedings 17th European Photovoltaic Solar Energy Conference, (2001)

4. H. Jin, K.J. Weber and A.W. Blakers, 'Depassivation of different orientation $\mathrm{Si}-\mathrm{SiO}_{2}$ following Rapid Thermal Annealing', this conference. 